\title{
Differences in Executive Functions and Problem Solving Styles of Protracted Sober and Relapsed Alcohol-dependent Patients
}

\author{
Sabri Burhanoglu ${ }^{1}$, Gokben Hizli Sayar ${ }^{{ }^{*}}$, Umut Isik ${ }^{2}$, Zehra Arikan $^{2}$, Behcet Cosar ${ }^{2}$ and Erdal Isik ${ }^{2}$ \\ ${ }^{1}$ Department of Psychiatry, Uskudar University, Istanbul, Turkey \\ ${ }^{2}$ Department of Psychiatry, Gazi University, Ankara, Turkey
}

"Corresponding author: Gökben Hızlı Sayar, Uskudar University NP Istanbul Hospital, Alemdag Cad. Siteyolu sk No: 27 Umraniye, Istanbul 34768 , Turkey, Tel: 902166330633; Fax: 902166341250; E-mail: gokben.hizlisayar@uskudar.edu.tr

Received date: Apr 2, 2014, Accepted date: May 15, 2014, Published date: May 20, 2014

Copyright: ( $) 2014$ Burhanoglu S, et al. This is an open-access article distributed under the terms of the Creative Commons Attribution License, which permits unrestricted use, distribution, and reproduction in any medium, provided the original author and source are credited

\begin{abstract}
In this study, it is aimed to compare the executive functioning and problem solving styles of relapsed alcoholdependent and protracted sober patients and to evaluate the potential clinical factors that act on the duration of sobriety. Fifty-six male patients meeting the DSM-IV alcohol dependence criteria included in the study. All patients were in sobriety period, classified as 32 of them in acute sobriety (relapsed after a maximum period of 6 months sobriety and just completed 3 weeks of detoxification) and 24 of them as protracted sobriety group (sober for a minimum period of 12 months). To evaluate the executive functions and problem solving styles Stroop test, Hanoi Tower Test and Problem Solving Inventory were applied. No significant differences found between two groups regarding executive functions. The protracted sobers were found to use "reflective" and "planfulness" styles more than the relapsed group. There was not any correlation between executive function and cumulative drinking, length of sobriety, educational status, age, alcohol dependency in the family, duration of illness, the amount of daily drinking, and amount of hospitalization. It is concluded that problem solving styles may play a role in staying sober as the "reflective" and "planfulness" styles were being used significantly more in the protracted sober group. Executive functioning which had been shown to be distorted in alcohol-dependent patients did not differ in relapsed and protracted sobriety. Further studies are needed to receive these results to be a determinant in the duration of sobriety.
\end{abstract}

Keywords: Alcohol dependence; Executive functions; Problem solving styles; Sobriety

\section{Introduction}

Alcohol dependence is associated with neurocognitive deficits related to pathological changes in structure, metabolism, and function of the brain $[1,2]$. Researchers suggest that $33-50 \%$ percent of people with alcohol use disorders exhibit detectable cognitive or motor impairments [3]. Studies in alcohol-dependent subjects usually show impairments in attention, memory, learning, visuospatial and language skills, psychomotor speed, new learning and memory, executive functioning, and emotional adjustment and affect processing $[4,5]$. In a recent study duration of heavy drinking and total period of abstinence were found to be the best predictors of cognitive and emotional function in alcoholism [6].

Although it is reported that skills like visuospatial learning, short term and declarative memory, response inhibition, learning, primary motor skills, perception and decision making are impaired in alcoholdependent subjects; it is not clear that how and when the impairment begins [2,7]. Crews et al. have stated that progressive changes in neuropsychological function may be related to alterations in gene expression, neuronal remodeling, and neurotoxicity [8]. These changes may play a role in the cognitive impairment during the alcoholism process.

Problem solving is an executive function that is impaired in alcohol-dependent subjects [9]. Problem solving function may be considered as an important factor in achieving remission and relapse prevention. According to D'Zurilla et al., individuals can be classified according to whether they have a "positive" or "negative" orientation towards problems and by their primary social problem solving style, with the three most common problem-solving styles being a "rational approach" to problems, an "impulsive-careless" style, or "problem avoidance" style [10]. A number of researches examining problemsolving have utilized the Problem Solving Inventory (PSI) of Heppner et al. [11] which is one of the most widely used self-report measures of applied problem solving. The initial factor analysis of the PSI revealed three factors: (a) problem-solving confidence, (b) approach-avoidance style, and (c) personal control. People who perceive themselves as effective problem solvers (having confidence and personal control, approaching problems; having low PSI scores) differ significantly from those who perceive themselves as ineffective (lacking confidence and personal control, avoiding problems; having high PSI scores) on a range of cognitive, affective, and behavioral variables [12]. Maladaptive problem solving exists when individuals have a negative problem orientation such as impulsive-careless or avoidant styles [10]. Maladaptive social problem solving has found to be associated with alcohol and other substances related problems [13]. Several studies have identified significant relationships between impulsive/careless and avoidant styles and alcohol related disorders among high school and college students [14]. Demirbas et al. reported increased rates of avoidant, self-confidence and impulsive thinking styles in alcoholdependent subjects [15]. Previous researchers suggest that interventions that enhance problem solving may hold promise for reducing risk for alcohol related problems $[9,16]$. 
This study aims to compare the executive functions and problem solving styles in relapsed and protracted sober patients with a diagnosis of alcohol dependence and to explore the possible factors that act on length of sobriety.

\section{Methods}

\section{Subject selection}

A total of 56 patients being treated at the Gazi University Psychiatry Clinic, Alcohol and Substance Abuse Treatment Unit in Turkey were included in the study. All patients met DSM-IV criteria for alcohol dependence and were screened for the presence of Axis I psychiatric disorders using the Mini International Neuropsychiatric InterviewPlus [17]. Approval had received from Gazi University local ethic board and written consents obtained from the subjects. All 56 patients accepted to participate.

Study included 18-65 aged male patients meeting DSM-IV criteria for alcohol dependence. Exclusion criteria were being diagnosed with substance abuse other than alcohol and nicotine, having clinically significant cognitive deficits or comorbid major psychiatric disorder like schizophrenia, bipolar disorder, mood disorder, dementia, other organic mental disorders and alcohol-induced amnestic syndrome and sobriety duration less than 3 weeks.

\section{Procedure}

Drinking status was assessed in terms of "protracted sobriety" and "relapse". Relapse was defined as consumption of any alcohol on at least three consecutive days. Drinking below this measure was defined as "laps". Protracted sobriety was defined as the absence of alcohol use without lapses during the last 12 months. Relapse group was taken into the study after a three-week detoxification treatment.

\section{Instruments}

All subjects were given a self-report questionnaire form and asked about their sociodemographic characteristics, age of first drink, age of regular alcohol use, the duration of the longest period of sobriety, family history of alcoholism and psychiatric disorders. Daily amount of alcohol consumption and the lifetime cumulative amount of alcohol intake of each patient has calculated with the equation suggested by Gul et al. [18].

$$
\mathrm{F}=0.05 \mathrm{~B}+0.12 \mathrm{~W}+0.45 \mathrm{~S}
$$

f: daily amount of alcohol use

B group drinks (beer): with 5\% alcohol inside

W group drinks (wine): with $12 \%$ alcohol inside

S group drinks (containing high alcohol): with $40 \%$ alcohol inside

For determining the executive functions and problem solving functions, Stroop Test, Tower of Hanoi Test and Problem Solving Inventory has been used.

\section{Stroop test:}

Developed by Stroop at 1935. It states the ability of an individual to change the perceptive configuration under the changing demands and a distorting affect, to suppress a habitual behavior pattern and to present unusual behavior [19]. In this study TBAG form of Stroop test was used [20].

\section{Tower of Hanoi test}

Tower of Hanoi is a test evaluating the prefrontal cortex functions and it is especially useful in the evaluation of problem solving. It was developed by Simon [21]. Successful task performance requires that individuals plan their moves to achieve the goal state and restrict the tendency to focus on short-term goals. Five disc systems are commonly used as a hard test in the normal population. In this study, 4 disc and wooden version of the test was used. Rating techniques differ in different studies. In this study, it is expected that the test should end at minimum 15 moves with 4 discs. More than 45 moves are accepted as a failure.

\section{Problem solving inventory}

Developed by Heppner and Peterson in 1982 [11]. It is a self-report inventory that the individual evaluated himself for his problem solving styles. It is applicable on adolescents and adults. For every item, patient is asked how frequent he/she behaves like indicated in the test. The PSI is designed to assess an individual's perception of problem solving skill and not actual problem solving skills. The PSI consists of 35 statements. For each statement, respondents use a 6 point scale with statement ( $1=$ strongly agree, $6=$ strongly disagree). The total score range is 32 to 198. Low scores represent positive appraisals of problem solving ability. Fifteen items are negatively worded and require reserve scoring. Sahin et al. study examined the psychometric properties of the PSI in a Turkish cultural context, specifically with regard to normative, reliability, and validity data [22]. Although the original PSI is consisted of three factors; problem solving confidence, approach avoidance and personal control, the Turkish version of the PSI consist of six factors; impulsive style, reflective style, problem-solving confidence, avoidant style, monitoring, planfulness [22].

First of the six factors was composed of nine items. Four of the five items from the original Personal Control factor, and five items from the original Approach-Avoidance factor. This factor reflected an Impulsive Style of problem solving and was labeled as such. An example item is "When confronted with a problem, I tend to do the first thing that I can think of to solve it." The second, fourth, and fifth factors consisted of items primarily from the original ApproachAvoidance factor. The second factor consisted of five items seemed to reflect a reasonable or reflective style of problem solving, and was labeled Reflective Style. An example is, "When making a decision, I weigh the consequences of each alternative and compare them against each other." The fourth factor consisted of four items seemed to reflect avoidant strategies, and was labeled Avoidant Style. An example is "When a solution to a problem was unsuccessful, I do not examine why it did not work." The fifth factor consisted of three items and was labeled Monitoring. An example is "After I have tried to solve a problem with a certain course of action, I take time and compare the actual outcomes to what I thought should have happened." The third factor consisted of six items and was named Problem-Solving Confidence. An example is "When faced with a novel situation, I have confidence that I can handle problems that may arise." The sixth factor consisted of four items and was labeled Planfulness. An example is "I make decisions, and I am happy with them later."

The factor loadings of the six-factor solution ranged from .43 to .77 . The alphas coefficients for the six factors were $.78, .76, .74, .69, .64$, 
Citation: Burhanoglu S, Hizli Sayar G, Isik U, Arikan Z, Cosar B et al. (2014) Differences in Executive Functions and Problem Solving Styles of Protracted Sober and Relapsed Alcohol-dependent Patients. Brain Disord Ther 3: 123. doi:10.4172/2168-975X.1000123

Page 3 of 6

and .59 , respectively. The interscale correlations ranged from 0.09 to 0.51 . Thus, the six new factors seem to be internally consistent and are sufficiently different to warrant separate scales [22].

\section{Statistical analysis}

Data was evaluated with SPSS 11.0. Frequency test was used for the range of the sociodemographic characteristics. To compare the sociodemographic characteristics of the short and protracted sober groups Yates chi square and Fisher Exact Test, to compare the clinical variables Mann-Whitney $U$ test were used. Pearson correlation analysis was used to determine the level and the direction of the correlation between clinical variables and Stroop and Hanoi tower test performances. $p$ values smaller than 0.05 are accepted as statistically significant.

\section{Results}

Fifty-six male patients included in the study. Patients were divided into two groups according to their drinking status. First group consisted of relapsed patients after less than 6 months of sobriety, and the second group is long-term sobers with more than 1 years of sobriety. Relapsed subjects were 32 in number (57\%) and protracted sobers were 24 (42\%). Age distributions, educational level, occupational and marital status of the groups were not significantly different. The interval of sobriety ranged from 21 to 30 days with a mean of $26.2 \pm 3.23$ days for the relapsed group as they were recruited in the study after 3 weeks detoxification period. For the protracted sobriety group, the mean duration of sobriety was $1203.5 \pm 1102.5$ days (Table 1).

\begin{tabular}{|l|l|l|l|}
\hline & Relapsers & Protracted sobers & $\mathrm{p}$ value \\
\hline Mean age (years) & $43.75 \pm 9.07$ & $46.50 \pm 6.88$ & $\mathrm{p}=0.15$ \\
\hline Chronicity of alcoholism (years) & $15.06 \pm 8.02$ & $18.46 \pm 8.61$ & $\mathrm{p}=0.070$ \\
\hline Age of first alcohol intake (years) & $1.75 \pm 4.50$ & $15.75 \pm 5.08$ & $\mathrm{p}=0.868$ \\
\hline Age of regular alcohol consumption(years) & $26.28 \pm 8.13$ & $24.17 \pm 5.74$ & $\mathrm{p}=0.539$ \\
\hline Daily alcohol consumption (grams) & $233.0 \pm 74.02$ & $333.96 \pm 183.51$ & $\mathrm{p}=0.051$ \\
\hline Cumulative alcohol consumption (kg) & $1444.60 \pm 867.79$ & $2241.71 \pm 1307.29$ & $\mathrm{p}=0.030^{*}$ \\
\hline Cigarette smoking (packets/day $x$ year) & $30.81 \pm 14.21$ & $36.33 \pm 19.7$ & $\mathrm{p}=0.312$ \\
\hline
\end{tabular}

Table 1: Drinking state of the relapsers and protracted sobers.

Note: Values are (mean \pm standard deviation).

* Mann-Whitney U. Significantly different between groups, $\mathrm{p}<0.05$

There was no significant difference between relapsed and long-term sober groups for the average age of first use of alcohol and the average age at which the patient begin to drink regularly. Difference in average amount of alcohol consumed in a day were quite close to be significant for the two groups $(\mathrm{p}=0.051)$. Cumulative quantity of alcohol consumption differed significantly $1444.6 \pm 867.8$ kilograms and $2241.7 \pm 1307.3$ kilograms in relapsed and protracted sober groups, respectively $(\mathrm{p}=0.03)$. Chronicity of alcohol-dependency did not differ between groups with a mean duration of $15.06 \pm 8.02$ and $18.46 \pm$ 8.61 years in relapsed and protracted sober groups, respectively $(\mathrm{p}=0.07)$.

Mean scores in the reflective and planfulness styles subscales of PSI were significantly lower for protracted sober group (p:0.043 and p: 0,026 , respectively). Higher scores indicate negative perceptions of one's problem-solving ability, indicating reflective and planfulness styles were perceived to be utilized more by long term sobers. Mean scores of PSI subscales of the groups are given on Table 2.

\begin{tabular}{|l|l|l|l|}
\hline & Relapsers & $\begin{array}{l}\text { Protracted } \\
\text { sobers }\end{array}$ & $\mathrm{p}$ value \\
\hline Avoidant style & $4.38 \pm 1.27$ & $4.50 \pm 1.24$ & $\mathrm{p}=0.745$ \\
\hline Impulsive style & $3.41 \pm 1.10$ & $3.47 \pm 1.11$ & $\mathrm{p}=0.765$ \\
\hline Reflective style & $2.77 \pm 1,13$ & $2.16 \pm 0.91$ & $\mathrm{p}=0.043^{*}$ \\
\hline
\end{tabular}

\begin{tabular}{|l|l|l|l|}
\hline Monitoring style & $2.49 \pm 1.26$ & $2.37 \pm 1,26$ & $p=0.719$ \\
\hline $\begin{array}{l}\text { Problem solving } \\
\text { confidence style }\end{array}$ & $2.61 \pm 0.74$ & $2.60 \pm 0.82$ & $p=0.967$ \\
\hline Planfulness style & $2.72 \pm 1.21$ & $2.04 \pm 0.87$ & $p=0.026^{*}$ \\
\hline
\end{tabular}

Table 2: Mean scores of PSI subscales

Note: Values are (mean \pm standard deviation)

* Significantly different between groups, $\mathrm{p}<0.05$

When compared for executive functions, no significant difference was found between two groups for Stroop Test performances. Pearson correlation test which was used to compare the Stroop Test performances with age and cumulative drinking did not show any significance either.

Majority, $66.1 \%(n=37)$ of the patients completed the Tower of Hanoi Test at their first try, and $26.8 \%(\mathrm{n}=15)$ of the patients completed the same test at their second try. Four of the patients $(7.1 \%)$ could not complete the Tower of Hanoi Test. No significant difference was found between the Tower of Hanoi Test measures (number of total moves, illegal moves, total test time and duration of thinking before the first move) between relapsed and protracted sober groups. Measures related to Tower of Hanoi Test are given on Table 3.

\begin{tabular}{|l|l|l|l|}
\hline & Relapsers & Protracted sobers & $p$ value \\
\hline
\end{tabular}




\begin{tabular}{|c|c|c|c|c|c|c|}
\hline & 1st try & 2nd try & 1st try & 2nd try & $\begin{array}{l}\text { Compar } \\
\text { ison of } \\
\text { 1st tries }\end{array}$ & $\begin{array}{l}\text { Comparis } \\
\text { on of } 2 n d \\
\text { tries }\end{array}$ \\
\hline $\begin{array}{l}\text { Total } \\
\text { moves }\end{array}$ & $\begin{array}{l}16.33 \pm \\
7.98\end{array}$ & $\begin{array}{l}16.73 \quad \pm \\
9.23\end{array}$ & $19 \pm 7.99$ & $19 \pm 8.87$ & 0.330 & 0.601 \\
\hline $\begin{array}{l}\text { Time to } \\
\text { first } \\
\text { move } \\
\text { (second } \\
\text { ) }\end{array}$ & $\begin{array}{l}9.83 \pm \\
13.72\end{array}$ & $\begin{array}{ll}3.64 & \pm \\
4.67 & \end{array}$ & $6.21 \pm 4.01$ & $3.5 \pm 1.91$ & 0.256 & 0.458 \\
\hline $\begin{array}{l}\text { Total } \\
\text { time to } \\
\text { complet } \\
\text { e test } \\
\text { (second } \\
\text { ) }\end{array}$ & $\begin{array}{l}140.78 \\
\pm 84.37\end{array}$ & $\begin{array}{l}133.27 \pm \\
60.83\end{array}$ & $\begin{array}{l}139.52 \quad \pm \\
59.97\end{array}$ & $\begin{array}{l}156.25 \quad \pm \\
49.32\end{array}$ & 0.693 & 0.513 \\
\hline $\begin{array}{l}\text { Number } \\
\text { of } \\
\text { illegal } \\
\text { moves }\end{array}$ & $\begin{array}{l}3.22 \pm \\
2.92\end{array}$ & $\begin{array}{ll}1.90 & \pm \\
1.30 & \end{array}$ & $2.21 \pm 2.04$ & $1.25 \pm 1.50$ & 0.362 & 0.422 \\
\hline
\end{tabular}

Table 3: Tower of Hanoi measures of relapsers and protracted sobers

Note: Values are (mean \pm standard deviation)

* Significantly different between groups, p 0.05

There was no correlation with the Pearson correlation test between Stroop and Hanoi tests and age, education level, amount of daily or cumulative alcohol consumption, length of sobriety, family history of alcoholism and the number of hospitalizations.

\section{Discussion}

Alcohol dependence is a relapsing-remitting disorder. The aim of the treatment is to achieve remission, prolong the remission time and prevent relapses. Previous studies reported that the effective problemsolving skills can reduce lifetime alcohol use $[9,10,23]$.

The results of the study indicate that subjects who perceived their problem solving style as less planful and less reflective were at greater risk to relapse compared to the ones who did not perceive their ways of problem solving as such. There was no difference observed in problem solving confidence, monitoring, impulsive and avoidant styles with relapse risk. According to these findings, it can be said that active involvement in problem solving is a predictor of a successful outcome. The reflective style subscale includes items that reflect a rational style of problem solving, such as, "I try to predict the outcome of the solution plan before I take action." Alcohol dependent patients who perceived their problem solving style as less reflective and less planfulness were at a greater risk of relapse. Thus, it can be suggested that remitters insist more on developing alternatives of possible solutions in a problem situation. On the other hand, two different studies found no correlation between relapse, sobriety period and problem solving styles $[15,24]$. Further studies seem to be needed to accept the problem solving styles as a remission-relapse deterministic component.

There was not any correlation between executive function and the cumulative amount of alcohol consumption, length of sobriety, educational status, age, history of alcohol dependency in family, duration of alcohol dependency, amount of daily alcohol intake and numbers of previous hospitalizations. Significant impairment across various cognitive functions reported remaining stable during the first year of abstinence from alcohol. Generally, dysfunction abates after one year of sobriety.

It is a momentous question that when, how and in what way the cognitive defects differ in alcohol-dependent patients. Stroop test is being widely used to determine the cognitive abilities in alcoholdependent patients. In the literature, the comparison studies of the alcohol-dependent patients with social drinkers and the heavy drinkers with mild drinkers show significant Stroop test performance differences [25]. Previous investigations of executive function in alcohol dependent subjects and social drinkers have not always produced consistent results [26]. There is a lack of agreement on rates of recovery on cognitive functions by abstinence [27]. The recovery of cognitive skills was found to depend on the length of abstinence. Brandt et al reported that psychomotor skills and short-term memory improved significantly with prolonged abstinence, long-term memory was impaired even after seven years of continuous sobriety [28].

In the literature, there is not always a relation between sobriety period and neurocognitive test performances [29-31]. In our study, no significance found between the relapsed and protracted sober groups for the Stroop test performances. This result is similar with the literature and points out the irreversibility of the Stroop test performance which is thought to be distorted in alcohol-dependent patients [32].

Recently, for a superior evaluation of the executive functions like problem solving and achieving target, tower tests were recommended [33]. It is suggested that the tests evaluating the executive functions which are dynamic and functional should be well designed and effective at the psychological processes like the usage of the planning strategies and problem solving [34]. Tower tests are thought to include the ability to attempt focused target behaviour, develop strategic sequential planning and application [35]. In the literature tower tests were not used frequently to evaluate the executive functions in alcohol-dependent patients.

London Tower test was used to determine the planning and working memory functions of the Korsakoff and non-Korsakoff alcoholics, and it was seen that the Korsakoff group alcoholics had worse performances than the non-Korsakoff group and the nonKorsakoff group had worse performances than the non-alcoholic group [36]. Many studies have shown that recently detoxified alcoholic persons perform poorly on tasks thought to be sensitive to frontal lobe damage, supporting the hypothesis that the frontal lobes are highly vulnerable to chronic alcohol consumption. However, it appeared that most of the executive tasks used in these studies also involved nonexecutive components and these tasks had been shown to be impaired as a result of non-frontal lobe lesions. Results of Noel et al. study suggested that alcoholics performed worse than controls in almost all tasks assessing executive functions. However, their mean processing speeds a nonexecutive functioning were found to be normal. Their data support the idea that the cognitive deficits in recently detoxified sober alcohol-dependent subjects are due, at least partly, to frontal lobe dysfunction. The results of the Hanoi Tower test used in our study support the literature and the performances of the Hanoi Tower and the Stroop test were similar in relapsed and sober groups. In prospective studies, 6-month sobriety period found to be long enough for abstainers' executive performances to return to normal $[30,37]$. Normalization by sobriety suggests that executive impairments should not be viewed as a premorbid risk factor for becoming an alcohol-dependent but rather as the consequences of the 
neurotoxic effects of alcohol on the cognition. It was also shown that the preexisting executive impairment of relapser's increased, even with only limited drinking resumption [30].

As for problem solving modalities and the test performances, there is no correlation between the Stroop Test and problem solving style. There is a correlation between the illegal move number in the Hanoi Tower test and impulsive style of problem solving styles. This means an impulsive person moves without thinking if the move is valid or not. In the correlation analysis between Stroop and Hanoi Tower test by dividing the problem solving styles to two (intended to harmonize, not intended to harmonise), we did not find any correlation.

This study has some limitations. As our study has no control group, the difference between alcohol-dependent patients and the normal group has not mentioned. As this is not a prospective study, it is also possible that the participants may have differences in their prefrontal cortical functioning, and thus executive functions, prior to the onset of alcohol dependency. The protracted sober group was chosen from patients attending the group therapy sessions of our clinic; therefore it is unclear that this situation may have any effect on the nature of sobriety.

\section{Conclusion}

It is concluded that problem solving styles may play a role in staying sober as the "reflective" and "planfulness" styles were being used significantly more in the protracted sober group. Executive functioning which had been shown to be distorted in alcoholdependent patients did not differ in relapsed and protracted sobriety. Further studies are needed to accept these results to be a determinant in the duration of sobriety.

\section{References}

1. Walvoort SJ, Wester AJ, Egger JI (2013) [The neuropsychology of cognitive functions in alcohol abstinence]. Tijdschr Psychiatr 55: 101-111.

2. Noël X, Brevers D, Bechara A (2013) A neurocognitive approach to understanding the neurobiology of addiction. Curr Opin Neurobiol 23: 632-638.

3. Arciniegas D, Beresford TP (2001) Neuropsychiatry: An Introductory Approach. Cambridge: Cambridge University Press.

4. Naim-Feil J, Fitzgerald PB, Bradshaw JL, Lubman DI, Sheppard D (2014) Neurocognitive deficits, craving, and abstinence among alcoholdependent individuals following detoxification. Arch Clin Neuropsychol 29: 26-37.

5. Dry MJ, Burns NR, Nettelbeck T, Farquharson AL, White JM (2012) Dose-related effects of alcohol on cognitive functioning. PLoS One 7 e50977.

6. Fitzpatrick LE, Crowe SF (2013) Cognitive and emotional deficits in chronic alcoholics: a role for the cerebellum? Cerebellum 12: 520-533.

7. Kopera M, Wojnar M, Brower K, Glass J, Nowosad I, et al. (2012) Cognitive functions in abstinent alcohol-dependent patients. Alcohol 46: 665-671.

8. Crews FT, Collins MA, Dlugos C, Littleton J, Wilkins L, et al. (2004) Alcohol-induced neurodegeneration: when, where and why? Alcohol Clin Exp Res 28: 350-364.

9. Demirbas H, Ilhan IO, Dogan YB (2012) Ways of problem solving as predictors of relapse in alcohol dependent male inpatients. Addict Behav 37: 131-134.

10. D'Zurilla TJ, Nezu AM, Maydeu-Olivares A (2002) Social problemsolving inventory-revised (SPSI-R): Technical manual. North Tonawanda, NY: MHS.
11. Heppner PP, Heppner PC (1982) The development and implications of a personal-problem solving inventory. Journal of Counseling Psychology 29: 66-75.

12. Heppner PP, Hillerbrand ET (1991) Problem-solving training: Implications for remedial and preventive training. In: Snyder CR, editor. Handbook of social and clinical psychology. New York: Pergamon Press.

13. Tucker JS, D'Amico EJ, Wenzel SL, Golinelli D, Elliott MN, et al. (2005) A prospective study of risk and protective factors for substance use among impoverished women living in temporary shelter settings in Los Angeles County. Drug Alcohol Depend 80: 35-43.

14. Jaffee WB, D'Zurilla TJ (2009) Personality, problem solving, and adolescent substance use. Behav Ther 40: 93-101.

15. Demirbas H, Ilhan IÖ, Dogan YB (2004) Alkol bagimlisi hastalarda bagimlilik sürecinin problem çözme yollari ile iliskisi (Relation of ways of problem solving and addiction in alcohol dependent patients). Bagimlilik Dergisi, Journal of Dependence 5: 8-11.

16. Sorsdahl K, Stein DJ, Carrara H, Myers B (2014) Problem solving styles among people who use alcohol and other drugs in South Africa. Addict Behav 39: 122-126.

17. Sheehan DV, Lecrubier Y, Sheehan KH, Amorim P, Janavs J, et al. (1998) The Mini-International Neuropsychiatric Interview (M.I.N.I.): the development and validation of a structured diagnostic psychiatric interview for DSM-IV and ICD-10. J Clin Psychiatry 59 Suppl 20: 22-33.

18. Gül S, Akvardar Y, Taș G, Tuncel P (2005) [The diagnostic validity of screening tests and laboratory markers in alcohol use disorders]. Turk Psikiyatri Derg 16: 3-12

19. Stroop JR (1935) Studies of interference in serial verbal reactions. Journal of Experimental Psychology 18: 643-662.

20. Karakas S, Erdogan E, Sak L, Soysal AS, Ulusoy T, et al. (1999) Stroop Testi TBAG Formu: Türk kültürüne standardizasyon calismalari, güvenirlik ve geçerlik (Stroop Test TBAG Form: Standardisation for Turkish Culture, Reliability and Validity). Klinik Psikiyatri Dergisi 2: 75-88

21. Simon HA (1975) The functional equivalence of problem-solving skills. Cognitive Psychology 7: 268-288.

22. Sahin N, Sahin NH, Heppner P (1993) Psychometric properties of the problem solving inventory in a group of Turkish university students. Cognitive Therapy and Research 17: 381-396.

23. Jaffee WB, D'Zurilla TJ (2009) Personality, problem solving, and adolescent substance use. Behav Ther 40: 93-101.

24. Moser AE, Annis HM (1996) The role of coping in relapse crisis outcome: a prospective study of treated alcoholics. Addiction 91: 1101-1113.

25. Stavro K, Pelletier J, Potvin S (2013) Widespread and sustained cognitive deficits in alcoholism: a meta-analysis. Addict Biol 18: 203-213.

26. Field M, Mogg K, Mann B, Bennett GA, Bradley BP (2013) Attentional biases in abstinent alcoholics and their association with craving. Psychol Addict Behav 27: 71-80.

27. Montgomery C, Fisk JE, Murphy PN, Ryland I, Hilton J (2012) The effects of heavy social drinking on executive function: a systematic review and meta-analytic study of existing literature and new empirical findings. Hum Psychopharmacol 27: 187-199.

28. Brandt J, Butters N, Ryan C, Bayog R (1983) Cognitive loss and recovery in long-term alcohol abusers. Arch Gen Psychiatry 40: 435-442.

29. Moriyama Y, Mimura M, Kato M, Yoshino A, Hara T, et al. (2002) Executive dysfunction and clinical outcome in chronic alcoholics. Alcohol Clin Exp Res 26: 1239-1244.

30. Pitel AL, Rivier J, Beaunieux H, Vabret F, Desgranges B, et al. (2009) Changes in the episodic memory and executive functions of abstinent and relapsed alcoholics over a 6-month period. Alcohol Clin Exp Res 33: 490-498.

31. Zinn S, Stein R, Swartzwelder HS (2004) Executive functioning early in abstinence from alcohol. Alcohol Clin Exp Res 28: 1338-1346. 
Citation: Burhanoglu S, Hizli Sayar G, Isik U, Arikan Z, Cosar B et al. (2014) Differences in Executive Functions and Problem Solving Styles of Protracted Sober and Relapsed Alcohol-dependent Patients. Brain Disord Ther 3: 123. doi:10.4172/2168-975X.1000123

Page 6 of 6

32. Tedstone D, Coyle K (2004) Cognitive impairments in sober alcoholics: performance on selective and divided attention tasks. Drug Alcohol Depend 75: 277-286.

33. Sullivan JR, Riccio CA, Castillo CL (2009) Concurrent validity of the tower tasks as measures of executive function in adults: a meta-analysis. Appl Neuropsychol 16: 62-75.

34. Marcovitch S, Zelazo PD (2009) A hierarchical competing systems model of the emergence and early development of executive function. Dev Sci 12: $1-18$.

35. Souza R, Ignácio FA, Cunha FC, Oliveira DL, Moll J (2001) [Contributions to the neuropsychology of executive behavior: performance of normal individuals on the Tower of London and Wisconsin tests]. Arq Neuropsiquiatr 59: 526-531.

36. Joyce EM, Robbins TW (1991) Frontal lobe function in Korsakoff and non-Korsakoff alcoholics: planning and spatial working memory. Neuropsychologia 29: 709-723.

37. Pitel AL, Chanraud S, Rohlfing T, Pfefferbaum A, Sullivan EV (2012) Face-name association learning and brain structural substrates in alcoholism. Alcohol Clin Exp Res 36: 1171-1179. 